\title{
A Filter of Selecting Candidate Schools
}

\author{
Yanqin Huang \\ School of North China Electric Power University, Baoding 071000, China \\ 1041087586@qq.com
}

Keywords: AHP, Hierarchical Structure, Discriminant Matrix.

\begin{abstract}
In this paper, the entire work is to establishing a model .Behind that, we are supposed to determine the optimal investment strategy, in order to give suggestions on how to allocate donations on America Education.
\end{abstract}

\section{Introduction}

With the development of social economy, more and more successful entrepreneurs start to focus on philanthropic educational investment. After researching for several famous cases of educational investment, we realize the investment is tightly associated with economy. Education will continue to predominate in the investment requirements for the revival of more rapid U.S. economic growth [1]. During the process of an educational investment, how to estimate or judge universities and allocate the donation is a very tough step. As thus, establishing a complete model to study an optimal investment strategy is of great importance.

\section{Model Overview}

The AHP2 is a structured technique for organizing and analyzing complex decisions, based on mathematics and psychology [2]. The basic idea of its principle is to split the complicated problem via building a hierarchical structure, according to the characteristic of the problem. Then build a discriminant matrix level by level and decide the weight occupied by each element of the sub-level beneath a parent principle level. Finally, compute with the combined weight of each principle and form the final policy.

\subsection{Step 1: Constructing the Hierarchical Structure}

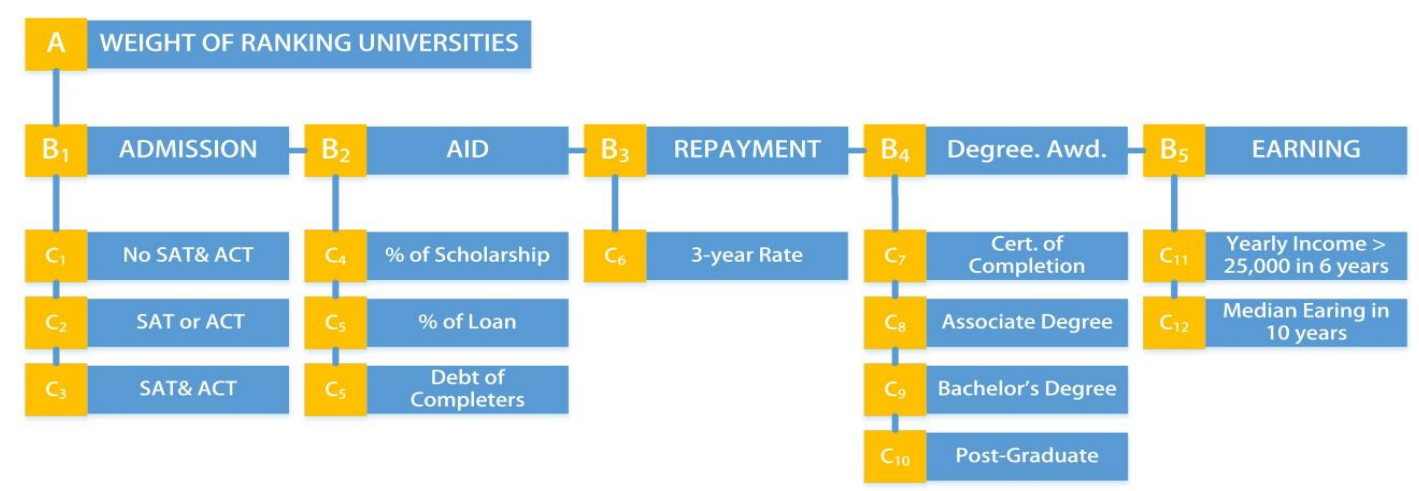

Figure 1 Constructed Hierarchical Structure

The hierarchies showed in Figure 1 is constructed with a comprehensive ranking of the general level of aggregation of a university. In this figure, Admission, Aid, Repayment, (Predominant) Degree Awarded, Earning form the next level which is directly connected with our target strategy. For example, the Admission is divided into 3 parts in its sub-level, which work together to decide how the university performs on admission. On the whole, the all the properties are distributing like an up-side down tree.

\subsection{Step 2: Constructing the Discriminant Matrix}

The hierarchies structure is a mapping of different factors, but the in the principle level, different properties take up different weight, which means their effects are diverse. 
While determining the weight of one factors among all the peer ones, the major difficulty is the quantification of them. Suppose we are comparing the influence on factor $\mathrm{Z}$ of $\mathrm{n}$ factors $(\mathrm{X}=\{x l, L$, $\left.x_{n}\right\}$ ), how to provide trustable statistic data? Saaty and his co-operators suggest to construct

discriminant matrix which compares the factors by pairs. In this way, every time we choose two factors $\mathrm{xi}$ and $x j$, and use aij to represent the ratio of the effect of $\mathrm{xi}$ and $x j$ on $\mathrm{Z}$. The result of the comparison will be used to construct a result matrix $A=(a i j) n \times n$, which is named Paired Compared Discriminant Matrix (Discriminant Matrix for short). On how to determine the value of aij, Saaty suggests to use number 1 to 9 and their reciprocals as a scale [2]. Here is table 1.

Table 1. The Definition of Scales

\begin{tabular}{|c|c|}
\hline Scale & Definition \\
\hline 1 & Of the same importance \\
\hline 3 & The former counts a little more \\
\hline 5 & The former counts more obviously \\
\hline 7 & The former counts more strongly \\
\hline 9 & The former is extremely important \\
\hline $2,4,6,8$ & The median of the adjacent definition above \\
\hline reciprocals & If the ratio of $x i$ and $x j$ is $a i j$, then the ratio of $x j$ and $x i$ will be $a j i=1 / a i j$ \\
\hline
\end{tabular}

From psychological surveys, more scales will distract people's judgement and increase the difficulty of determine and risk of fake data. Saaty has told us it's better to use 1 to 9 and their reciprocals as a scale, according to many experiments.

\subsection{Step 3: Level Simple Sequence and Compatibility Test}

Discriminant Matrix A correspond to the feature vector $\mathrm{W}$ of Maximum Eigenvalue $\lambda$ max. After normalizing, it becomes the weight of a factor among peer ones related to the parent level. This process is called Level Simple Sorting.

The constructing of the Paired Comparison Discriminant Matrix above will certainly reduce the disturbance of other factors, and mapping the influence of factors objectively. But when it comes to the integration of all results, it is unavoidable to meet some incompatibility. If the result is positive, then elements of matrix A are supposed to satisfy:

For all $i, j, k=1,2,3, \ldots n, a i j \times a j k=a i k$.

The steps of compatibility test is listed in Table 2 and table 3.

Table 2 Definition of Parameters

\begin{tabular}{|c|c|}
\hline Parameters & Definition \\
\hline$\lambda \max$ & Maximum Eigenvalue \\
\hline$A$ & Discriminant Matrix \\
\hline$C I$ & Compatibility Index \\
\hline$n$ & Rank of the Discriminant Matrix \\
\hline$R$ & Feature vector of the Maximum Eigenvalue \\
\hline$\lambda^{\prime} \max$ & Random Compatibility Index \\
\hline$C R$ & Average of Maximum Eigenvalue \\
\hline
\end{tabular}

Table 3. Value of RIs

\begin{tabular}{|c|c|c|c|c|c|c|c|c|c|}
\hline $\mathrm{n}$ & 1 & 2 & 3 & 4 & 5 & 6 & 7 & 8 & 9 \\
\hline $\mathrm{RI}$ & 0 & 0 & 0.58 & 0.90 & 1.12 & 1.24 & 1.32 & 1.41 & 1.45 \\
\hline
\end{tabular}

This is how we get the value of RIs: Construct 500 sample matrix with random methods, choose from 1 to 9 (and their reciprocals) to form a Reciprocal Matrix R, and compute its Maximum Eigenvalue $\lambda$ 'max, and define 


$$
\begin{aligned}
& R I=\frac{\lambda_{\max }^{\prime}-n}{n-1} \text { Compute Compatibility Ratio } C R \\
& C R=\frac{C I}{R I} \quad \text { When } C R<0.10 \text {, we consider the compatibility of the matrix to be acceptable }
\end{aligned}
$$

(Acceptable Discriminant Matrix), or a correction of the Discriminant Matrix is necessary.

\subsection{Step 4: Use Standardized Data to Sort Schools}

(Without universities on HCM2)

Standardization

$$
\text { result }=\frac{x-\bar{x}}{\sqrt[2]{\frac{1}{n} \sum\left(x_{i}-\bar{x}\right)^{2}}}
$$

Sort schools after computing with weight from Step 1 to 3.

\begin{tabular}{|c|c|c|c|c|c|c|c|c|}
\hline$A$ & $B 1$ & $B 2$ & $B 3$ & $B 4$ & B5 & Vector of Max-Eigen & Weight & \\
\hline$B 1$ & 1 & 1 & 1 & 4 & 1 & 0.4252 & 0.1945 & \multirow{4}{*}{$\begin{array}{c}\lambda \max =7.2647 \\
C I=0.0426 \\
R I=1.24 \\
C R=0.034\end{array}$} \\
\hline$B 2$ & 1 & 1 & 2 & 4 & 1 & 0.5039 & 0.2305 & \\
\hline B3 & 1 & $1 / 2$ & 1 & 5 & 3 & 0.5722 & 0.2618 & \\
\hline B4 & $1 / 4$ & $1 / 4$ & $1 / 5$ & 1 & $1 / 3$ & 0.3009 & 0.1377 & \\
\hline$B 5$ & 1 & 1 & $1 / 3$ & 3 & 1 & 0.3838 & 0.1755 & \\
\hline
\end{tabular}

\section{Numerical Computation}

Table 4. The Compatibility Test on Discriminant Matrix of Target Level

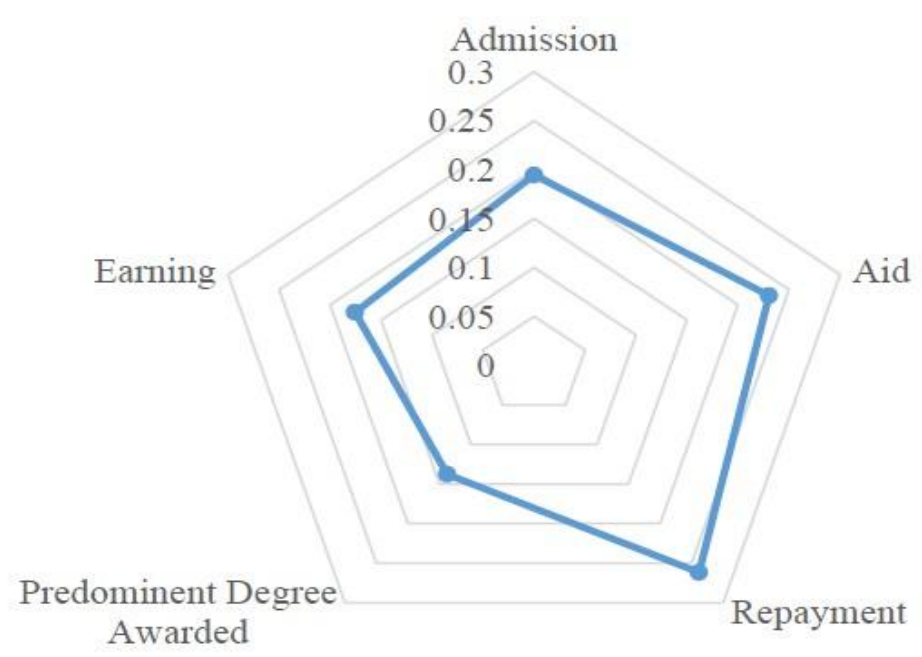

\begin{tabular}{|c|c|c|c|c|c|c|}
\hline$B 2$ & $C 4$ & $C 5$ & C6 & Vector of Max-Eigen & Weight & \\
\hline C4 & 1 & 5 & 8 & 0.9713 & 0.7510 & \multirow{3}{*}{$\begin{array}{c}\lambda \max =3.0055 \\
C I=0.0021 \\
R I=0.58 \\
C R=0.047\end{array}$} \\
\hline$C 5$ & $1 / 5$ & 1 & 2 & 0.2092 & 0.1618 & \\
\hline C6 & $1 / 8$ & $1 / 2$ & 1 & 0.1127 & 0.0817 & \\
\hline
\end{tabular}

Figure 2 the Weight Distribution of Several Factors

Table 5. The Compatibility Test on Discriminant Matrix of Target Level 2 (one of all) 


\section{Conclusion}

After filtering with Model I, we analyzed top 10 from the list1 (order by Final Index), we find these schools at lists of University Ranking of US2, which means these schools have a great advantage in admitting better applicants and have a wider future after they graduate. From this aspect, our filter model has feasibility on this standard.

\section{References}

[1] Dale W. Jorgenson and Barbara M. Fraumeni, "Investment in Education and U.S. Economic Growth", Scand. J. of Economics 94, Supplement, 51-70, 1992.

[2] Wikipedia.org, "Analytic hierarchy process", Wikipedia, the free encyclopedia, Available at: https://en.wikipedia.org/wiki/Analytic_hierarchy_process (Accessed: Feb.1st 2016). 